ACCEPTED MANUSCRIPT

\title{
Reduced ion migration and enhanced photoresponse in cuboid crystals of methylammonium lead iodide perovskite
}

To cite this article before publication: Ayan A Zhumekenov et al 2018 J. Phys. D: Appl. Phys. in press https://doi.org/10.1088/1361-6463/aaefdf

\section{Manuscript version: Accepted Manuscript}

Accepted Manuscript is "the version of the article accepted for publication including all changes made as a result of the peer review process, and which may also include the addition to the article by IOP Publishing of a header, an article ID, a cover sheet and/or an 'Accepted

Manuscript' watermark, but excluding any other editing, typesetting or other changes made by IOP Publishing and/or its licensors"

This Accepted Manuscript is @ 2018 IOP Publishing Ltd.

During the embargo period (the 12 month period from the publication of the Version of Record of this article), the Accepted Manuscript is fully protected by copyright and cannot be reused or reposted elsewhere.

As the Version of Record of this article is going to be / has been published on a subscription basis, this Accepted Manuscript is available for reuse under a CC BY-NC-ND 3.0 licence after the 12 month embargo period.

After the embargo period, everyone is permitted to use copy and redistribute this article for non-commercial purposes only, provided that they adhere to all the terms of the licence https://creativecommons.org/licences/by-nc-nd/3.0

Although reasonable endeavours have been taken to obtain all necessary permissions from third parties to include their copyrighted content within this article, their full citation and copyright line may not be present in this Accepted Manuscript version. Before using any content from this article, please refer to the Version of Record on IOPscience once published for full citation and copyright details, as permissions will likely be required. All third party content is fully copyright protected, unless specifically stated otherwise in the figure caption in the Version of Record.

View the article online for updates and enhancements. 


\title{
Reduced Ion Migration and Enhanced
}

\author{
Photoresponse in Cuboid Crystals of
}

\section{Methylammonium Lead Iodide Perovskite}

Ayan A. Zhumekenov, ${ }^{\dagger, \perp}$ Md Azimul Haque ${ }^{\ddagger, \perp}$ Jun Yin,${ }^{\dagger}$ Ahmed M. El-Zohry, ${ }^{\dagger}$ Kwang Jae Lee ${ }^{\dagger}$

Ibrahim Dursun, ${ }^{\dagger}$ Omar F. Mohammed, ${ }^{\dagger}$ Derya Baran, ${ }^{\ddagger}$ osman M. Bakr ${ }^{\dagger, *}$

${ }^{\dagger}$ King Abdullah University of Science and Technology(KAUST), Physical Sciences and

Engineering Division (PSE), Thuwal 23955-6900, Saudi Arabia

$\$$ King Abdullah University of Science and Technology (KAUST), KAUST Solar Center,

Physical Sciences and Engineering Division (PSE), Thuwal 23955-6900, Saudi Arabia

$\perp$ A.A.Z. and M.A.H. contributed equally to this work.

\section{Corresponding Author}

*E-mail: osman.bakr@kaust.edu.sa 


\section{Introduction}

Facets are the means by which a crystalline material interacts with the outer world. Facetdependent photocatalytic activity, electrical conductivity, and optical properties in a number of semiconductor crystals have recently been reported. ${ }^{1-5}$ Such facet effects have been observed also in halide perovskites, ${ }^{6-9}$ an emerging class of solution-processed semiconductor materials with exceptional optoelectronic properties. ${ }^{10-12}$ Evidence has been mounting over the last two years, implicating the orientation of facets of individual grains in thin films of $\mathrm{CH}_{3} \mathrm{NH}_{3} \mathrm{PbI}_{3}(\mathrm{Cl})$ perovskite solar cells to their photovoltaic performance. ${ }^{6,7}$ Yet the sub-micron sizes and generally random alignment of grains, as well as effects at grain boundaries obstruct the systematic study of charge transport properties in halide perovskites along different crystallographic planes (or directions) in polycrystalline films. Such studies require sizable single crystals with distinct facets, ensuring unhindered charge-carrier characterization, ${ }^{13,14}$ while serving as a model platform to gain more fundamental insights into the mixed conduction (electronic and ionic) behavior of halide perovskites. $^{15,16}$

Methylammonium lead iodide $\left(\mathrm{CH}_{3} \mathrm{NH}_{3} \mathrm{PbI}_{3}\right)$ with a bandgap of $1.52 \mathrm{eV}$, suitable for solar cell applications, is the most extensively studied halide perovskite material. ${ }^{13,14,17}$ There has been several reports on facet-dependent electronic behavior of $\mathrm{CH}_{3} \mathrm{NH}_{3} \mathrm{PbI}_{3}$ perovskites recently. ${ }^{18-20}$ However, reported studies mainly focused on the typical rhombo-dodecahedral (or shortly, rhombic) shape of $\mathrm{CH}_{3} \mathrm{NH}_{3} \mathrm{PbI}_{3}$ single crystals, which presents natural facets oriented along the (200) and (112) crystallographic planes. On the other hand, the electronic behavior of the structurally important (002) plane, which slice the perovskite structure along the octahedral diagonals, remains largely unexplored. This scarcity is directly attributed to the difficulty of realizing crystals with the (002) exposed facets. 
To this end, in this work, we developed a low-temperature growth of $\mathrm{CH}_{3} \mathrm{NH}_{3} \mathrm{PbI}_{3}$ perovskite crystals of cuboid shape with naturally exposed facets oriented along the (002) and (110) planes. These crystals were utilized to fabricate two-terminal devices on their (002) facets. The dark and light $I-V$ characteristics of the devices were contrasted to those fabricated on the (200) facets of typical rhombic $\mathrm{CH}_{3} \mathrm{NH}_{3} \mathrm{PbI}_{3}$ perovskite crystals. Furthermore, the current characteristics along different directions in both crystal shapes were also tested. Our findings revealed a substantially different extent of ionic and electronic charge transport behavior in cuboid and rhombic crystals.

\section{Results and Discussions}

\section{Synthesis and Characterization}

$\mathrm{CH}_{3} \mathrm{NH}_{3} \mathrm{PbI}_{3}$ perovskite is generally grown into fhombic shape with facets oriented along the (112) and (200) planes. ${ }^{19,21}$ In order to alter the crystal shape and the orientation of exposed facets, only a few strategies have been proposed to date. ${ }^{22,23}$ The addition of oleylamine or increasing the concentration of iodide-ions in the precursor solution: both were shown to induce the growth of cuboid crystals with the (002) and (110) facets exposed. ${ }^{22-24}$ Yet these strategies that expose the sought-after facets, entail that the crystals be grown either at relatively high temperatures $\left(>115^{\circ} \mathrm{C}\right)$, quite above the phase-transition point of $\mathrm{CH}_{3} \mathrm{NH}_{3} \mathrm{PbI}_{3}\left(55^{\circ} \mathrm{C}\right),{ }^{25}$ or from non-stoichiometric (I-rich) precursor ratios. Both conditions are known to adversely affect the crystal quality. $25-27$ Thus, we believe that low-temperature growth from stoichiometric solutions can provide higher quality single crystals which would eventually be reflected in better device performance. 


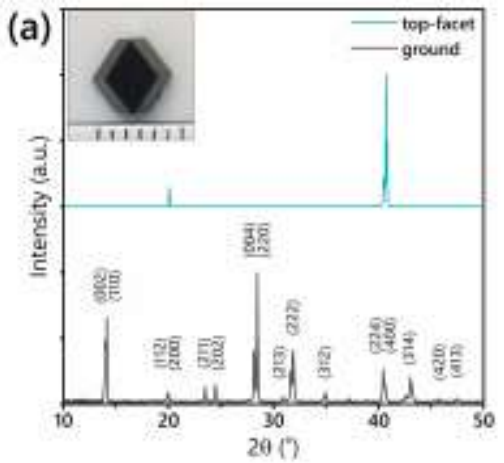

(b)

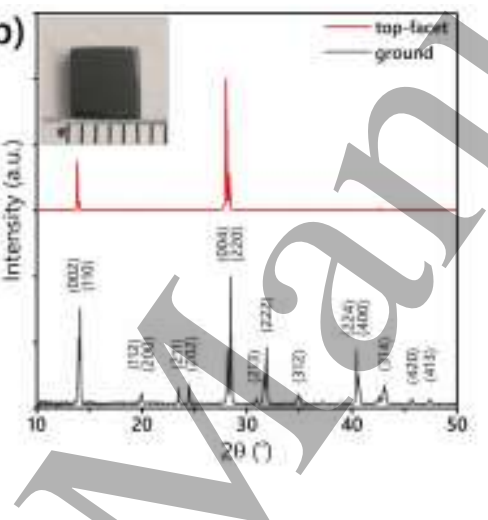

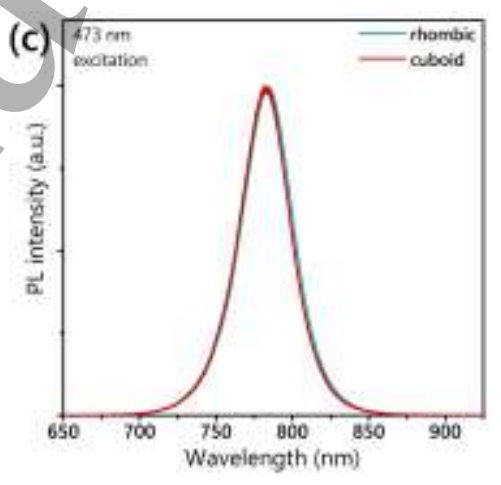

In this work, we attempted to conduct all crystallizations below $105^{\circ} \mathrm{C}$. Namely, we grew rhombic $\mathrm{CH}_{3} \mathrm{NH}_{3} \mathrm{PbI}_{3}$ perovskite crystals by inverse temperature crystallization (ITC) ${ }^{28-31}$ method at around $100^{\circ} \mathrm{C}$. In the case of cuboid $\mathrm{CH}_{3} \mathrm{NH}_{3} \mathrm{PbI}_{3}$ perovskite crystals, we utilized $N, N$-di- $n$ butylformamide (DBF) as a solvent achieving ITC at around $65^{\circ} \mathrm{C}$. Both crystals were rinsed with acetone when extracted from the solution which endowed them with a specular surface. Smooth surfaces help ensure a good contact with the electrodes.

Figure 1. X-ray Diffraction (XRD) patterns of the top-facet and ground form of $\mathrm{CH}_{3} \mathrm{NH}_{3} \mathrm{PbI}_{3}$ crystals with (a) rhombo-dodecahedral (or rhombic) and (b) cuboid shapes. Insets: photographs of the corresponding crystals. (c) Photoluminescence (PL) spectra of $\mathrm{CH}_{3} \mathrm{NH}_{3} \mathrm{PbI}_{3}$ crystals measured in reflectance mode with $473 \mathrm{~nm}$ laser as the excitation source.

The powder X-ray Diffraction (XRD) patterns of the ground crystals confirmed the presence of single phase of tetragonal $\mathrm{CH}_{3} \mathrm{NH}_{3} \mathrm{PbI}_{3}$ perovskite $(a \approx 8.86 \AA, c \approx 12.66 \AA)$ in both rhombic and cuboid crystals (Figure 1a,b). ${ }^{17,28}$ The steady-state photoluminescence (PL) spectra from the top surface of two crystals were also found to be identical, with a slight $(\sim 2 \mathrm{~nm})$ shift in peak positions (Figure 1c). The time-resolved PL upon above-bandgap excitation $\left(\lambda_{\text {exc }}=400 \mathrm{~nm}\right)$ revealed similar charge-carrier dynamics on the surface of two crystals, resulting of average lifetime values about $3 \mathrm{~ns}$, which are comparable to the previously reported ones (Figure S2a). ${ }^{32,33}$ 


\section{Planes of facets in rhombo-dodecahedral (rhombic) $\mathrm{CH}_{3} \mathrm{NH}_{3} \mathrm{Pbl}_{3}$ crystals:}

(a)

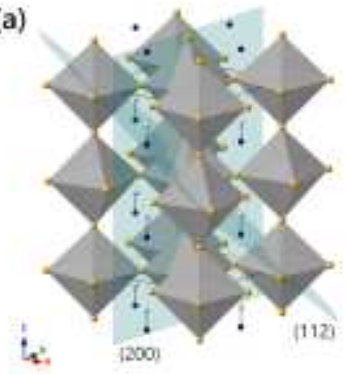

(b)

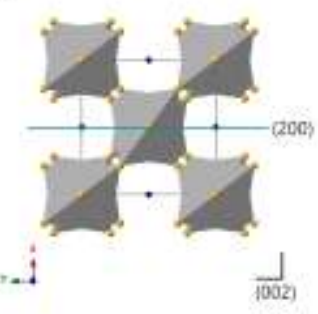

(c)

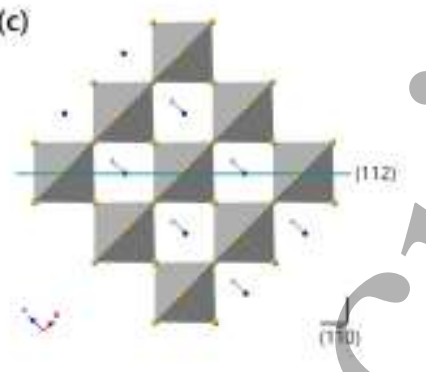

(d)

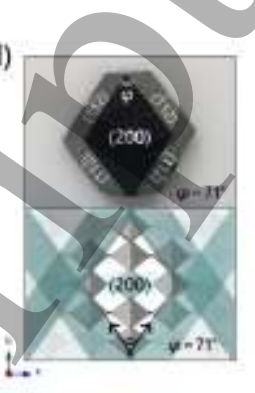

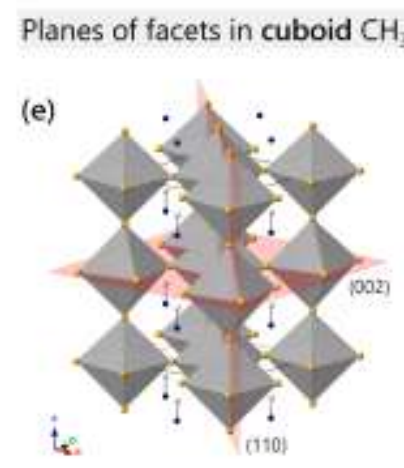

(f)

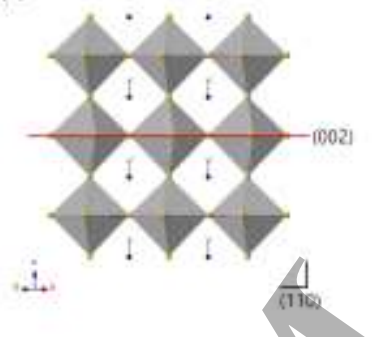

(g)

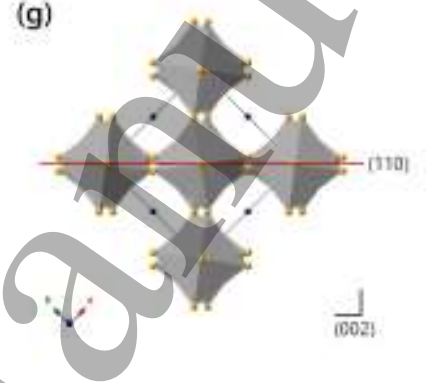

(h)

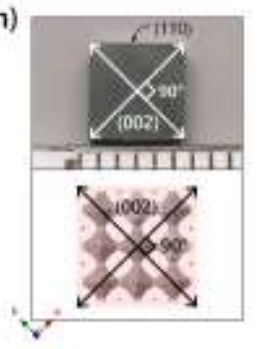

Figure 2. Crystallographic planes of naturally exposed facets in $\mathrm{CH}_{3} \mathrm{NH}_{3} \mathrm{PbI}_{3}$ perovskite crystals of (a) rhombo-dodecahedral (or rhombic) and (e) cuboid shapes. Horizontal views of the (b) (200), (c) (112), (f) (002), and (g) (110) planes. Relation between the shape and the crystal structure in $\mathrm{CH}_{3} \mathrm{NH}_{3} \mathrm{PbI}_{3}$ perovskite crystals: the top-facet in (d) rhombo-dodecahedral (or rhombic) crystals correspond to the (200) plane, while in (h) cuboid crystals - to the (002) plane. The structures were generated based on the crystallographic data reported by Stoumpos et al. ${ }^{17}$

In order to determine the crystallographic orientation of the naturally exposed facets, we performed XRD measurements by aligning the crystals with top-facets parallel to a sample holder plane. The diffraction pattern of the rhombic crystal showed signals at around $20^{\circ}$ and $40^{\circ}$ only (Figure 1a). Peaks at $2 \theta=19.96^{\circ}$ and $20.06^{\circ}$ were assigned to the (112) and (200) planes, respectively, and peaks at $2 \theta=40.48^{\circ}$ and $40.70^{\circ}$ - to the (224) and (400) planes, respectively. We note that in the tetragonal crystal system $\{112\}$ and $\{200\}$ families of planes are not parallel (Figure 2a-c), while in cubic system they converge into a single $\{110\}$ family of planes. Thus, the 
presence of paired peaks might basically arise due to some symmetry breaking during the phasetransition of single crystals from cubic $(P m-3 m)$ to tetragonal $(I 4 / \mathrm{mcm})$ system. ${ }^{22,34,35}$ Nonetheless, we propose the top-facet of the rhombic crystals to be mainly (200)-oriented (Figure 2d), as the relative peak intensities of $\{200\}$ planes were found to be higher than that of $\{112\}$ planes. Also the higher symmetry of the (200) plane compared to the (112) plane is more likely to result in a rhombus at the crystal center (Figure 2d). Such facet orientation is in line with previous reports on $\mathrm{CH}_{3} \mathrm{NH}_{3} \mathrm{PbI}_{3}$ perovskite single crystals grown in the same shape. ${ }^{36,37}$

For the cuboid $\mathrm{CH}_{3} \mathrm{NH}_{3} \mathrm{PbI}_{3}$ perovskite crystals, distinct diffraction signals appear at around $14^{\circ}$ and $28^{\circ}$ (Figure 1b). As in the case of rhombic crystals, these signals consisted of paired peaks. Namely, we observed two adjacent peaks at $2 \theta=13.86^{\circ}$ and $14.02^{\circ}$ corresponding to the (002) and (110) planes, respectively, and peaks at $2 \theta=28.04^{\circ}$ and $28.33^{\circ}$ corresponding to the (004) and (220) planes, respectively. Originated from symmetry breaking of (001) plane of cubic system, the orthogonal (002) and (110) planes slice the perovskite structure in a similar manner (Figure 2e-g), but differ from each other by the degree of rotational symmetry. As the (002) plane is fourfold symmetric, it is expected to extend into a perfect-square facet; however, the two-fold symmetric (110) plane would rather grow into a rectangular facet. Therefore, we assume the topfacet of cuboid crystals to be mainly oriented along the (002) plane (Figure 2h), which is also corroborated with the higher relative peak intensities of $\{002\}$ planes over $\{110\}$ planes.

As can be seen, rhombic and cuboid crystals each expose a set of two similar facets: (112)/(200) and (002)/(110), respectively (Figure 2). Though these sets are distinctively different from each other in their manner to slice the perovskite structure. The exposure of (002) and (110) facets when using DBF as the solvent can be explained with the presence of two $n$-butyl chains in the DBF structure. Besides solvation of lead-complexes, bulky DBF molecules preferentially 
coordinate the more accessible (002) and (110) sites of the forming crystal lattice. As a result, the crystal shape is defined with these slower growing planes. This mechanism is similar to that proposed for the growth of cuboid crystals using long-chain oleylamine ligand. ${ }^{22}$ We would also like to note that bulky DBF molecules could be less prone to intercalate into the perovskite structure rather than $\gamma$-butyrolactone (GBL) molecules, as the size of the latter can fit the perovskite inorganic cage between the octahedra (Figure S1). These growth conditions, as well as different facet orientation of the crystals, can bring unexpected ramifications in electronic behavior.

\section{Device Performance}
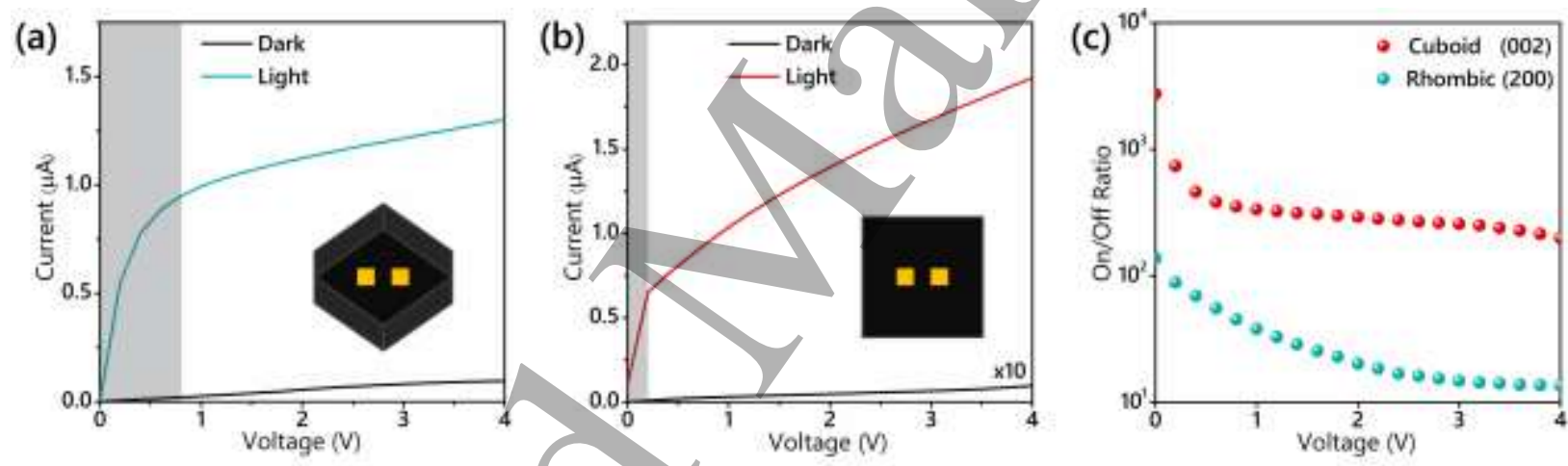

Figure 3. Dark and light $I-V$ characteristics of the two-terminal device on the (a) (200) facet of rhombic crystal and the (b) (002) facet of cuboid crystal. Shaded regions in (a) and (b) show mixed conduction range in these crystals. Insets of (a) and (b): the corresponding device architectures used for measurements. (c) Bias dependence of the on/off ratio measured in two samples.

To study the contrast in electronic behavior between rhombic and cuboid crystals, we fabricated two terminal planar devices on the corresponding (200) and (002) facets, respectively, by depositing gold electrodes. Both crystals formed ohmic contacts with the electrodes (Figure S2b). Figure 3a,b shows the dark current and photocurrent of the devices upon illuminations with white light of $2 \mathrm{~mW} \mathrm{~cm}^{-2}$. Cuboid crystals exhibited lower dark current ( $9 \mathrm{nA}$ at $4 \mathrm{~V}$ ) compared 
to rhombic crystals $(95 \mathrm{nA}$ at $4 \mathrm{~V})$. Suppressed dark current is a prerequisite feature for devices such as photodetectors for achieving high signal-to-noise ratios and operational reliability. ${ }^{38}$

In both crystals, the photocurrent exhibited a regime with a fast rise at lower voltages after which a saturation effect was observed with increasing bias. Noteworthy, the degree of photocurrent saturation in the case of rhombic crystals was higher than that in cuboid ones. In addition, this saturation regime in cuboid crystals starts at lower bias compared to rhombic crystals. Nonetheless, the observed effect of photocurrent saturation in both crystals can be attributed to the formation of a built-in electric field. ${ }^{37}$ It is well known that the conduction in halide perovskites is mixed (ionic and electronic). ${ }^{15,16,39}$ The photoconduction at low bias (shaded region in Figure 3a,b) before saturation is generally ascribed to mixed conduction, while in the saturation region to only electronic conduction. ${ }^{18}$ The built-in field is created due to ionic conduction, i.e. as a result of ions $\left(\mathrm{CH}_{3} \mathrm{NH}_{3}{ }^{+}\right.$and $\left.\mathrm{I}^{-}\right)$and vacancy migration. Under external applied bias, the ions and vacancies migrate to respective electrodes and this accumulation generates an internal field which is opposite in direction to the external applied field. ${ }^{20,40}$ This built-in field reduces the effective field leading to the decrease of the photocurrent slope (saturation). Thus, the higher photocurrent saturation in the case of rhombic crystals indicates a higher built-in field than in cuboid crystals, which implies a higher ionic migration. By calculating the relative ratio of ionic to electronic conductance, $r=G_{i} / G_{e}$, we semi-quantitatively estimated the effect of ionic migration in two crystals. The ratio for the rhombic crystal was found to be $\sim 3$ times higher than that for the cuboid one (Figure S3). However, it is worth mentioning that more accurate quantification of the ionic migration requires more advanced techniques to be utilized (e.g. impedance spectroscopy) ${ }^{15}$.

Next, we observed that the photocurrent for the cuboid crystals was higher than that for the rhombic crystals, reaching $1.9 \mu \mathrm{A}$ versus $1.3 \mu \mathrm{A}$, respectively, under $4 \mathrm{~V}$ bias (Figure 3a,b); 
which indicates their better performance under light. The reason is due to reduced ion migration: the lower internal field in cuboid crystals ensures greater enhancement of photocurrent with the applied bias. Furthermore, reduced ion migration induces less defects in the areas far away from electrodes,${ }^{41-43}$ further improving the photoconduction. Figure $3 \mathbf{c}$ shows the on/off ratio measured at different bias voltages. Cuboid crystals exhibited higher on/off ratio in the whole voltage range compared to rhombic ones. Lower on/off ratio at higher bias was observed for the rhombic crystals due to photocurrent saturation. We speculate that the observed improved electronic behavior of the (002) facet over (200) not only depends on the growth conditions (low-temperature and bulky chains in solvent molecules), but also could originate from the different nature of the corresponding planes and the associated surface effects (trap states, termination chemistry).

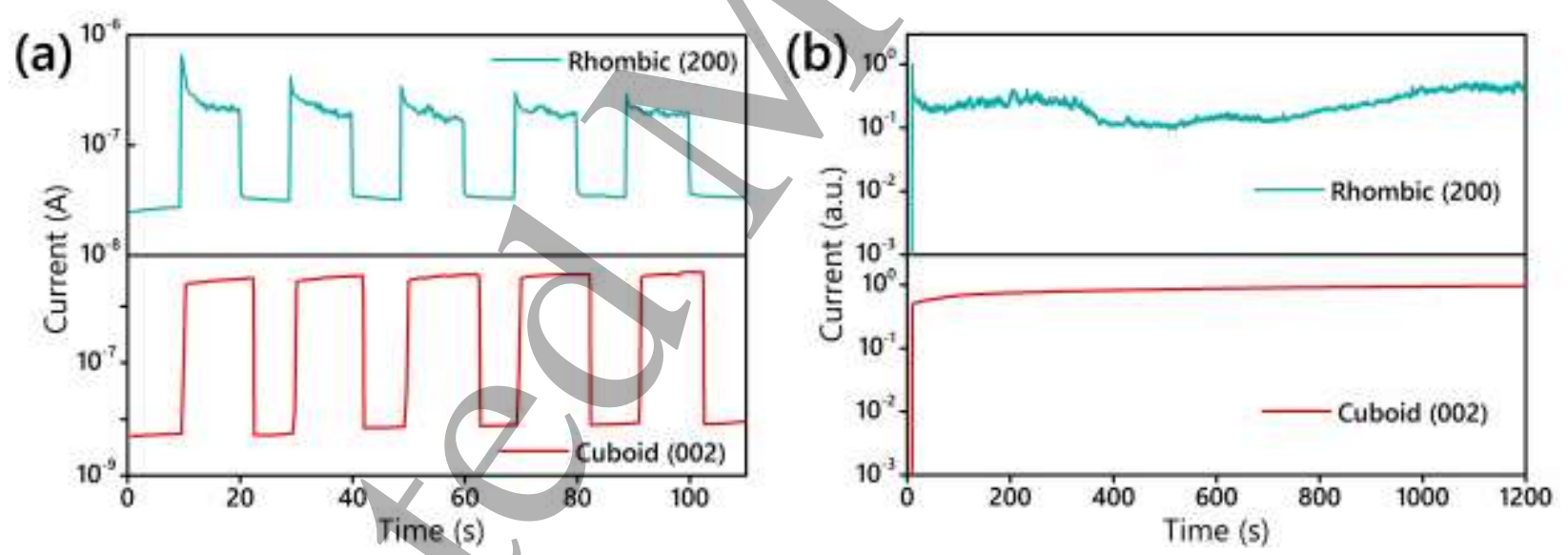

Figure 4. (a) Photoresponse under light pulses measured at $4 \mathrm{~V}$ bias. (b) Current stability measured under continuous illumination.

Time-dependent photocurrent measurements can shed more light on the conduction behavior of the present devices. For the rhombic crystals, there were steep jumps when the light was turned on (Figure 4a). Such behaviors have been reported to originate from the ion migration and carrier 
trapping/detrapping. ${ }^{44}$ Interestingly, in the case of cuboid crystals, stable photocurrents were observed as a consequence of a likely low degree of ion migration and defects under illumination. Furthermore, to check the photostability of the devices, photocurrent was recorded under constant illumination over $1200 \mathrm{~s}$ (Figure 4b). Cuboid crystals exhibited very stable behavior under constant illumination while rhombic ones showed unstable photocurrent. This instability in rhombic crystals can be ascribed to the higher concentration of ions and vacancies leading to the carrier trapping, scattering and recombination while the carriers drift. 9 Recent experimental evidence also suggests that interaction of photo-generated carriers can create iodine vacancies by propelling neutral iodine into nearby interstitial. ${ }^{45}$
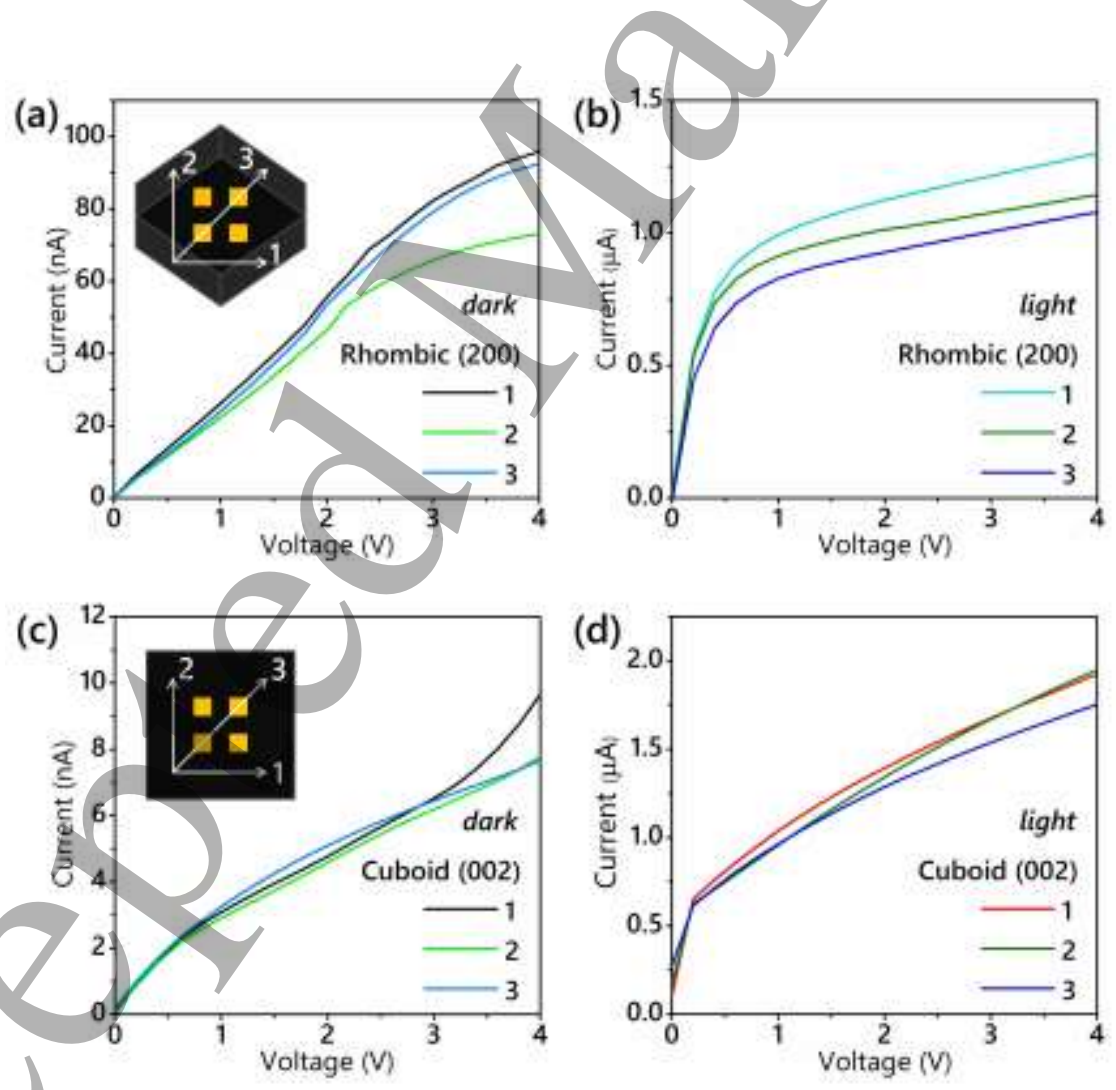

Figure 5. $I-V$ characteristics of the devices along different directions on the (200) facet of rhombic crystals (a) in dark and (b) under light; on the (002) facet of cuboid crystals (c) in dark and (d) under light. Insets of (a) and (c): the corresponding device architectures used for measurements. 
Recently, a number of studies reported some degree of electronic anisotropy on different facets of halide perovskite crystals, ${ }^{9,18-20,46}$ but electronic anisotropy along different directions on the same facet remains unexplored. In addition, theoretical studies predicted anisotropic mobility along different crystallographic directions. ${ }^{47,48} \mathrm{We}$ calculated the effective masses of hole and electron along different in-plane directions of $\mathrm{CH}_{3} \mathrm{NH}_{3} \mathrm{PbI}_{3}(100)$ and (001) slabs (Figure S4). In both cases, we did observe charge carrier effective mass variation with the chosen direction (Table S2). One would expect, this effective mass anisotropy feature should also be reflected in electronic transport properties. To verify this hypothesis, we deposited multiple electrodes on the crystal facets in order to measure $I-V$ characteristics along different in-plane directions (Figure 5). However, we did not observe a strong signature of charge transport anisotropy within a given crystal both in dark and under illumination (Figure S5,6). Namely, no significant variation of dark current and photocurrent with respect to the measurement direction in both rhombic and cuboid crystals was found. Nonetheless, we note that rhombic crystals, in contrast to cuboid crystals, showed saturation of dark current at high bias, implying that ion migration takes place in them even in the dark. It is worth mentioning that the conduction in hybrid perovskites is quite complex in nature due to the presence of the ion and vacancy migration as well as the surface states, which makes it challenging to observe electronic anisotropy experimentally by traditional techniques.

\section{Conclusions}

To summarize, we were able to achieve a facile low-temperature growth of cuboid crystals of $\mathrm{CH}_{3} \mathrm{NH}_{3} \mathrm{PbI}_{3}$ perovskite. The growth of such cuboid crystals enabled us to compare the optoelectronic behavior of two-terminal devices on their (002) facet to devices on the (200) facet that typically appear on rhombic $\mathrm{CH}_{3} \mathrm{NH}_{3} \mathrm{PbI}_{3}$ crystals. Cuboid crystals exhibited reduced ion 
migration, lower dark current, and significantly higher (and more stable) photocurrent compared to the rhombic crystals. We ascribe these striking differences in the device performance of cuboid and rhombic crystals to the facet orientations as well as the differing growth conditions. Finally, we tested each crystal to the possible effect of charge transport anisotropy along different directions on the same facet. However, despite theoretical predictions, we did not observe significant anisotropy both in dark and under light. More precise measurements eliminating the effects of surface defects and ion migration will be required to delineate the intrinsic charge transport anisotropy in halide perovskites.

\section{Experimental Section}

All chemicals were used as received without any further purification. Methylammonium iodide $\left(\mathrm{CH}_{3} \mathrm{NH}_{3} \mathrm{I}\right)$ was purchased from Dyesol Limited (Australia). Lead iodide $\left(\mathrm{PbI}_{2}, 99.999 \%\right.$ trace metal basis) and $\gamma$-butyrolactone (GBL, $\geq 99 \%$ ) were purchased from Sigma-Aldrich. $N, N$-di- $n$ butylformamide (DBF) was purchased from TCI(Tokyo, Japan). All experiments were conducted in ambient air at relative humidity of $\sim 60 \%$.

Growth of rhombic $\mathrm{CH}_{3} \mathrm{NH}_{3} \mathrm{PbI}_{3}$ crystals. The crystals were grown by inverse temperature crystallization (ITC) method following a slightly modified procedure of that reported by Saidaminov et al. ${ }^{28}$ Typically, $1.2 \mathrm{M}$ solution of $\mathrm{CH}_{3} \mathrm{NH}_{3} \mathrm{I} / \mathrm{PbI}_{2}$ in $\gamma$-butyrolactone (GBL) was prepared, filtered through $0.45 \mu \mathrm{m}$ pore size PTFE-filter and placed on a hot plate at $70^{\circ} \mathrm{C}$. Then the solution was gradually heated to $\sim 100^{\circ} \mathrm{C}$ and kept at this temperature until the formation of rhombo-dodecahedral (or rhombic) $\mathrm{CH}_{3} \mathrm{NH}_{3} \mathrm{PbI}_{3}$ crystals. The crystals can be grown into larger sizes by elevating the temperature further. Finally, we rinsed the crystals with acetone (1 time) to provide them a specular surface.

Growth of cuboid $\mathrm{CH}_{3} \mathrm{NH}_{3} \mathrm{PbI}_{3}$ crystals. The crystals were also grown by ITC method. An equimolar mixture of $\mathrm{CH}_{3} \mathrm{NH}_{3} \mathrm{I}$ and $\mathrm{PbI}_{2}$ was dissolved in $N, N$-di- $n$-butylformamide (DBF) by continuous stirring for 1 hour at $45^{\circ} \mathrm{C}$, and another 30 mins at room temperature. The obtained solution $(0.7 \mathrm{M})$ was filtered through $0.45 \mu \mathrm{m}$ pore size PTFE-filter and placed on a hot plate at 
$30^{\circ} \mathrm{C}$. Then the solution was gradually heated to $\sim 65^{\circ} \mathrm{C}$ and kept at this temperature until the formation of cuboid $\mathrm{CH}_{3} \mathrm{NH}_{3} \mathrm{PbI}_{3}$ crystals. The crystals can be grown into larger sizes by elevating the temperature further. Similarly to the rhombic crystals, the cuboid crystals were rinsed with acetone (1 time) to achieve a specular surface.

Characterization. X-ray diffraction (XRD) measurements were performed on a Bruker AXS D8 Advance diffractometer using $\mathrm{Cu}-\mathrm{K} \alpha$ radiation source. The steady-state photoluminescence (PL) was recorded in reflection mode on a Horiba JY LabRAM Aramis spectrometer using $473 \mathrm{~nm}$ laser as the excitation source. The time-resolved photoluminescence (TRPL) was recorded on a Horiba Jobin Yvon (DD-405L) using $400 \mathrm{~nm}$ pulsed laser diode as the excitation source (IRF $\approx 300 \mathrm{ps}$ ).

Device Fabrication and Characterization. $100 \mathrm{~nm}$ gold electrodes were deposited on the crystal surface by using a shadow mask. The channel length and width were $200 \mu \mathrm{m}$ each. $I-V$ characteristics and transient photocurrent were measured using Keithley 4200 semiconductor analyzer. A halogen light source with an intensity of $2 \mathrm{~mW} \mathrm{~cm}^{-2}$ was used for all measurements.

\section{Acknowledgements}

The authors gratefully acknowledge the funding support provided by King Abdullah University of Science and Technology (KÂUST).

\section{References}

(1) Huang, M. H.; Naresh, G.; Chen, H.-S. Facet-Dependent Electrical, Photocatalytic, and Optical Properties of Semiconductor Crystals and Their Implications for Applications. ACS Appl. Mater. Interfaces 2018, 10, 4-15.

(2) Liu, G.; Yu, J. C.; Lu, G. Q.; Cheng, H.-M. Crystal Facet Engineering of Semiconductor Photocatalysts: Motivations, Advances and Unique Properties. Chem. Commun. 2011, 47, 6763-6783.

(3) Debroye, E.; Van Loon, J.; Yuan, H.; Janssen, K. P. F.; Lou, Z.; Kim, S.; Majima, T.; Roeffaers, M. B. J. Facet-Dependent Photoreduction on Single Zno Crystals. J. Phys. Chem. Lett. 2017, 8, 340-346.

(4) Tan, C.-S.; Hsu, S.-C.; Ke, W.-H.; Chen, L.-J.; Huang, M. H. Silicon Wafers with FacetDependent Electrical Conductivity Properties. Angew. Chem. Int. Ed. 2017, 56, 15339-15343. 
(5) Zhu, J.; Fan, F. T.; Chen, R. T.; An, H. Y.; Feng, Z. C.; Li, C. Direct Imaging of Highly Anisotropic Photogenerated Charge Separations on Different Facets of a Single $\mathrm{BiVO}_{4}$ Photocatalyst. Angew. Chem. Int. Ed. 2015, 54, 9111-9114.

(6) Leblebici, S. Y.; Leppert, L.; Li, Y.; Reyes-Lillo, S. E.; Wickenburg, S.; Wong, E.; Lee, J.; Melli, M.; Ziegler, D.; Angell, D. K. et al. Facet-Dependent Photovoltaic Efficiency Variations in Single Grains of Hybrid Halide Perovskite. Nat. Energy 2016, 1, 16093.

(7) Eperon, G. E.; Ginger, D. S. Perovskite Solar Cells: Different Facets of Performance. Nat. Energy 2016, 1, 16109.

(8) Zheng, G.; Zhu, C.; Ma, J.; Zhang, X.; Tang, G.; Li, R.; Chen, Y.; Li, L.; Hu, J.; Hong, J. et al. Manipulation of Facet Orientation in Hybrid Perovskite Polycrystalline Films by Cation Cascade. Nat. Commun. 2018, 9, 2793.

(9) Zuo, Z.; Ding, J.; Zhao, Y.; Du, S.; Li, Y.; Zhan, X.; Cui, H. Enhanced Optoelectronic Performance on the (110) Lattice Plane of an $\mathrm{MAPbBr}_{3}$ Single Crystal. J. Phys. Chem. Lett. 2017, 8, 684-689.

(10) Grätzel, M. The Light and Shade of Perovskite Solar Cells. Nat. Mater. 2014, 13, 838.

(11) Park, N.-G.; Grätzel, M.; Miyasaka, T.; Zhu, K.; Emery, K. Towards Stable and Commercially Available Perovskite Solar Cells. Nat. Energy 2016, 1, 16152.

(12)Zhang, W.; Eperon, G. E.; Snaith, H. J. MetalHalide Perovskites for Energy Applications. Nat. Energy 2016, 1, 16048.

(13) Dong, Q.; Fang, Y.; Shao, Y.; Mulligan, P.; Qiu, J.; Cao, L.; Huang, J. Electron-Hole Diffusion Lengths $>175 \mu \mathrm{m}$ in Solution-Grown $\mathrm{CH}_{3} \mathrm{NH}_{3} \mathrm{PbI}_{3}$ Single Crystals. Science 2015, 347, 967-970.

(14) Shi, D.; Adinolfi, V.; Comin, R.; Yuan, M.; Alarousu, E.; Buin, A.; Chen, Y.; Hoogland, S.; Rothenberger, A.; Katsiev, K. et al. Low Trap-State Density and Long Carrier Diffusion in Organolead Trihalide Perovskite Single Crystals. Science 2015, 347, 519-522.

(15) Peng, W.; Aranda, C.; Bakr, O. M.; Garcia-Belmonte, G.; Bisquert, J.; Guerrero, A. Quantification of Ionic Diffusion in Lead Halide Perovskite Single Crystals. ACS Energy Lett. 2018, 3, 1477-1481.

(16) Yang, T.-Y.; Gregori, G.; Pellet, N.; Grätzel, M.; Maier, J. The Significance of Ion Conduction in a Hybrid Organic-Inorganic Lead-Iodide-Based Perovskite Photosensitizer. Angew. Chem. Int. Ed. 2015, 54, 7905-7910.

(17) Stoumpos, C. C.; Malliakas, C. D.; Kanatzidis, M. G. Semiconducting Tin and Lead Iodide Perovskites with Organic Cations: Phase Transitions, High Mobilities, and near-Infrared Photoluminescent Properties. Inorg. Chem. 2013, 52, 9019-9038.

(18) Zuo, Z.; Ding, J.; Li, Y.; Zhao, Y.; Du, S. Anisotropic Ionic Transportation Performances of (100) and (112) Planes in $\mathrm{MAPbI}_{3}$ Single Crystal. Mater. Res. Bull. 2018, 99, 466-470.

(19) Ding, J.; Jing, L.; Cheng, X.; Zhao, Y.; Du, S.; Zhan, X.; Cui, H. Design Growth of MAPbI 3 Single Crystal with (220) Facets Exposed and Its Superior Optoelectronic Properties. J. Phys. Chem. Lett. 2018, 9, 216-221. 
(20) Ding, J.; Du, S.; Cheng, X.; Jing, L.; Zhao, Y.; Zuo, Z.; Cui, H.; Zhan, X. Anisotropic Optoelectronic Performances on (112) and (100) Lattice Plane of Perovskite $\mathrm{MAPbI}_{3}$ Single Crystal. Mater. Chem. Phys. 2018, 204, 222-227.

(21) Liu, Y.; Zhang, Y.; Yang, Z.; Yang, D.; Ren, X.; Pang, L.; Liu, S. Thinness- and ShapeControlled Growth for Ultrathin Single-Crystalline Perovskite Wafers for Mass Production of Superior Photoelectronic Devices. Adv. Mater. 2016, 28, 9204-9209.

(22) Jao, M.-H.; Lu, C.-F.; Tai, P.-Y.; Su, W.-F. Precise Facet Engineering of Peroyskite Single Crystals by Ligand-Mediated Strategy. Cryst. Growth Des. 2017, 17, 5945-5952.

(23)Zhang, Y.; Huang, F.; Mi, Q. Preferential Facet Growth of Methylammonium Lead Halide Single Crystals Promoted by Halide Coordination. Chem. Lett. 2016, 45, 1030-1032.

(24)Zhumekenov, A. A.; Burlakov, V. M.; Saidaminov, M. I.; Alofi, A.; Haque, M. A.; Turedi, B.; Davaasuren, B.; Dursun, I.; Cho, N.; El-Zohry, A. M. et al. The Role of Surface Tension in the Crystallization of Metal Halide Perovskites. ACS Energy Lett. 2017, 2, 1782-1788.

(25) Jacobsson, T. J.; Schwan, L. J.; Ottosson, M.; Hagfeldt, A.; Edvinsson, T. Determination of Thermal Expansion Coefficients and Locating the Temperature-Induced Phase Transition in Methylammonium Lead Perovskites Using X-Ray Diffraction. Inorg. Chem. 2015, 54, 1067810685.

(26) Alarousu, E.; El-Zohry, A. M.; Yin, J.; Zhumekenov, A. A.; Yang, C.; Alhabshi, E.; Gereige, I.; AlSaggaf, A.; Malko, A. V.; Bakr, O. M. et al. Ultralong Radiative States in Hybrid Perovskite Crystals: Compositions for Submillimeter Diffusion Lengths. J. Phys. Chem. Lett. 2017, 8, 4386-4390.

(27) Uratani, H.; Yamashita, K. Charge Carrier Trapping at Surface Defects of Perovskite Solar Cell Absorbers: A First-Principles Study. J.Phys. Chem. Lett. 2017, 8, 742-746.

(28) Saidaminov, M. I.; Abdelhady, A. L.; Murali, B.; Alarousu, E.; Burlakov, V. M.; Peng, W.; Dursun, I.; Wang, L.; He, Y.; Maculan, G. et al. High-Quality Bulk Hybrid Perovskite Single Crystals within Minutes by Inverse Temperature Crystallization. Nat. Commun. 2015, 6, 7586.

(29) Kadro, J. M.; Nonomura, K.; Gachet, D.; Grätzel, M.; Hagfeldt, A. Facile Route to Freestanding $\mathrm{CH}_{3} \mathrm{NH}_{3} \mathrm{PbI}_{3}$ Crystals Using Inverse Solubility. Sci. Rep. 2015, 5, 11654.

(30) Liu, Y.; Yang, Z.; Cui, D.; Ren, X.; Sun, J.; Liu, X.; Zhang, J.; Wei, Q.; Fan, H.; Yu, F. et al. Two-Inch-Sized Perovskite $\mathrm{CH}_{3} \mathrm{NH}_{3} \mathrm{PbX}_{3} \quad(\mathrm{X}=\mathrm{Cl}, \mathrm{Br}, \mathrm{I})$ Crystals: Growth and Characterization. Adv. Mater. 2015, 27, 5176-5183.

(31) Hamill, J. C.; Schwartz, J.; Loo, Y.-L. Influence of Solvent Coordination on Hybrid OrganicInorganic Perovskite Formation. ACS Energy Lett. 2018, 3, 92-97.

(32) Grancini, G.; D'Innocenzo, V.; Dohner, E. R.; Martino, N.; Srimath Kandada, A. R.; Mosconi, E.; De Angelis, F.; Karunadasa, H. I.; Hoke, E. T.; Petrozza, A. $\mathrm{CH}_{3} \mathrm{NH}_{3} \mathrm{PbI}_{3}$ Perovskite Single Crystals: Surface Photophysics and Their Interaction with the Environment. Chem. Sci. 2015, 6, 7305-7310.

(33) Wu, B.; Nguyen, H. T.; Ku, Z.; Han, G.; Giovanni, D.; Mathews, N.; Fan, H. J.; Sum, T. C. Discerning the Surface and Bulk Recombination Kinetics of Organic-Inorganic Halide Perovskite Single Crystals. Adv. Energy Mater. 2016, 6, 1600551. 
(34) Beecher, A. N.; Semonin, O. E.; Skelton, J. M.; Frost, J. M.; Terban, M. W.; Zhai, H.; Alatas, A.; Owen, J. S.; Walsh, A.; Billinge, S. J. L. Direct Observation of Dynamic Symmetry Breaking above Room Temperature in Methylammonium Lead Iodide Perovskite. ACS Energy Lett. 2016, 1, 880-887.

(35) Whitfield, P. S.; Herron, N.; Guise, W. E.; Page, K.; Cheng, Y. Q.; Milas, I.; Crawford, M. K. Structures, Phase Transitions and Tricritical Behavior of the Hybrid Perovskite Methyl Ammonium Lead Iodide. Sci. Rep. 2016, 6, 35685.

(36) Dang, Y.; Liu, Y.; Sun, Y.; Yuan, D.; Liu, X.; Lu, W.; Liu, G.; Xia, H.; Tao, X. Bulk Crystal Growth of Hybrid Perovskite Material $\mathrm{CH}_{3} \mathrm{NH}_{3} \mathrm{PbI}_{3}$. CrystEngComm 2015, 17, 665-670.

(37)Lian, Z.; Yan, Q.; Lv, Q.; Wang, Y.; Liu, L.; Zhang, L.; Pan, S.; Li, Q.; Wang, L.; Sun, J.-L. High-Performance Planar-Type Photodetector on (100) Facet of $\mathrm{MAPbI}_{3}$ Single Crystal. Sci. Rep. 2015, 5, 16563.

(38) Saidaminov, M. I.; Haque, M. A.; Almutlaq, J.; Sarmah, S.; Miao, X.-H.; Begum, R.; Zhumekenov, A. A.; Dursun, I.; Cho, N.; Murali, B. et al. Inorganic Lead Halide Perovskite Single Crystals: Phase-Selective Low-Temperature Growth, Carrier Transport Properties, and Self-Powered Photodetection. Adv. Opt. Mater. 2016, 1600704.

(39) Zhao, Y.-C.; Zhou, W.-K.; Zhou, X.; Liu, K.-H.; Yu, D.-P.; Zhao, Q. Quantification of LightEnhanced Ionic Transport in Lead Iodide Perovskite Thin Films and Its Solar Cell Applications. Light Sci. Appl. 2017, 6, e16243.

(40) Guan, X.; Hu, W.; Haque, M. A.; Wei, N.; Liu, Z.; Chen, A.; Wu, T. Light-Responsive IonRedistribution-Induced Resistive Switching in Hybrid Perovskite Schottky Junctions. Adv. Funct. Mater. 2018, 28, 1704665.

(41) Deng, X.; Wen, X.; Lau, C. F. J.; Young, T.; Yun, J.; Green, M. A.; Huang, S.; Ho-Baillie, A. W. Y. Electric Field Induced Reversible and Irreversible Photoluminescence Responses in Methylammonium Lead Iodide Perovskite. J. Mat. Chem. C 2016, 4, 9060-9068.

(42)Zhao, Y.; Zhou, W.; Ma, W.; Meng, S.; Li, H.; Wei, J.; Fu, R.; Liu, K.; Yu, D.; Zhao, Q. Correlations between Immobilizing Ions and Suppressing Hysteresis in Perovskite Solar Cells. ACS Energy Lett. 2016, 1, 266-272.

(43)Li, C.; Guerrero, A.; Zhong, Y.; Gräser, A.; Luna, C. A. M.; Köhler, J.; Bisquert, J.; Hildner, R.; Huettner, S. Real-Time Observation of Iodide Ion Migration in Methylammonium Lead Halide Perovskites. Small 2017, 13, 1701711.

(44) Ono, L. K.; Raga, S. R.; Remeika, M.; Winchester, A. J.; Gabe, A.; Qi, Y. Pinhole-Free Hole Transport Layers Significantly Improve the Stability of $\mathrm{MAPbI}_{3}$-Based Perovskite Solar Cells under Operating Conditions. J. Mater. Chem. A 2015, 3, 15451-15456.

(45) Kim, G. Y.; Senocrate, A.; Yang, T.-Y.; Gregori, G.; Grätzel, M.; Maier, J. Large Tunable Photoeffect on Ion Conduction in Halide Perovskites and Implications for Photodecomposition. Nat. Mater. 2018, 17, 445-449.

(46) Cheng, X.; Jing, L.; Zhao, Y.; Du, S.; Ding, J.; Zhou, T. Crystal Orientation-Dependent Optoelectronic Properties of $\mathrm{MAPbCl}_{3}$ Single Crystals. J. Mater. Chem. C 2018, 6, 15791586. 
(47)Zhao, T.; Shi, W.; Xi, J.; Wang, D.; Shuai, Z. Intrinsic and Extrinsic Charge Transport in $\mathrm{CH}_{3} \mathrm{NH}_{3} \mathrm{PbI}_{3}$ Perovskites Predicted from First-Principles. Sci. Rep. 2016, 6, 19968.

(48) Meng, G.; Feng, Y.; Song, X.; Shi, Y.; Ji, M.; Xue, Y.; Hao, C. Theoretical Insight into the Carrier Mobility Anisotropy of Organic-Inorganic Perovskite $\mathrm{CH}_{3} \mathrm{NH}_{3} \mathrm{PbI}_{3}$. J. Electroanal. Chem. 2018, 810, 11-17. 